\title{
http://dx.doi.org/10.35381/i.p.v3i5.1367
}

\section{Impacto de los derivados de la caña de azúcar sobre las propiedades físico- mecánicas del hormigón}

\section{Impact of sugarcane derivatives on the physical-mechanical properties of concrete}

\author{
Sócrates Pedro Muñoz-Pérez \\ msocrates@crece.uss.edu.pe \\ Universidad Señor de Sipán, Pimentel, Chiclayo, Lambayeque \\ Perú \\ https://orcid.org/0000-0003-3182-8735 \\ Ramiro Stalin Coronel-Camino \\ caminors@crece.uss.edu.pe \\ Universidad Señor de Sipán, Pimentel, Chiclayo, Lambayeque \\ Perú \\ https://orcid.org/0000-0002-2593-792X \\ Julio César Vargas Villafuerte \\ vvillafuertejul@crece.uss.edu.pe \\ Universidad Señor de Sipán, Pimentel, Chiclayo, Lambayeque \\ Perú \\ https://orcid.org/0000-0002-7595-6862
}

Recibido: 05 de abril de 2019

Revisado: 17 de mayo de 2019

Aprobado: 20 de junio de 2020

Publicado: 31 de julio de 2020 


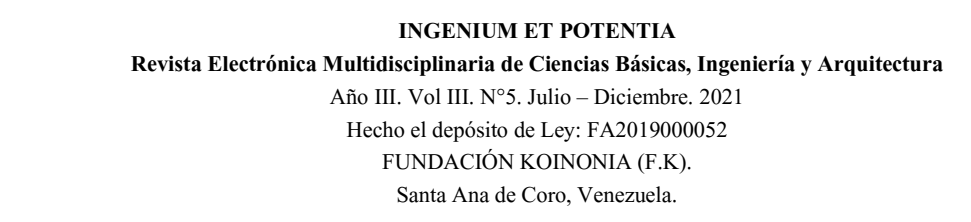

Sócrates Pedro Muñoz Pérez; Ramiro Stalin Coronel Camino; Julio César Vargas Villafuerte

\title{
RESUMEN
}

El presente artículo tiene como objetivo evaluar el comportamiento físico mecánico del hormigón con productos derivados de la caña de azúcar tales como (1) la ceniza de bagazo de caña de azúcar (CBCA) como reemplazo porcentual y gradual del cemento; y (2) la fibra de bagazo de caña de azúcar (FBCA) como reemplazo porcentual respecto al peso del agregado. Se revisó 46 artículos científicos referidos al tema entre la base de datos SCOPUS y SciELO, cuyos resultados encontrados fueron que al incorporar entre el $20 \%$ al $30 \%$ de CBCA incinerada entre $600^{\circ} \mathrm{C}$ y $800{ }^{\circ} \mathrm{C}$ mejora sustancialmente la trabajabilidad, resistencia a la compresión y flexión; por otra parte la incorporación de FBCA tratada (lavada y sumergida en hidróxido de calcio) en porcentajes que van del $0.5 \%$ al $1.5 \%$ respecto al peso del agregado, mejora también las propiedades de resistencia principalmente.

Descriptores: Ingeniería civil; construcción de viviendas; diseño arquitectónico. (Palabras tomadas de Tesauro UNESCO).

\begin{abstract}
This Article aims to assess the mechanical physical behaviour of concrete with sugarcane products such as (1) sugarcane bagasse ash (CBCA) as a percentage and gradual replacement of cement; and (2) sugarcane bagasse fiber (FBCA) as a percentage replacement relative to the weight of the aggregate. 46 scientific articles on the subject were reviewed between the SCOPUS database and SciELO, the results of which were found to incorporate between $20 \%$ and $30 \%$ of CBCA incinerated between $600 \mathrm{oC}$ and $800 \mathrm{oC}$ substantially improves workability, compressure resistance and flexion; on the other hand the incorporation of treated FBCA (washed and submerged in calcium hydroxide) in percentages ranging from $0.5 \%$ to $1.5 \%$ compared to the weight of the aggregate, also improves resistance properties mainly.
\end{abstract}

Descriptors: Civil engineering; housing construction; building design. (Words taken from UNESCO Thesaurus). 


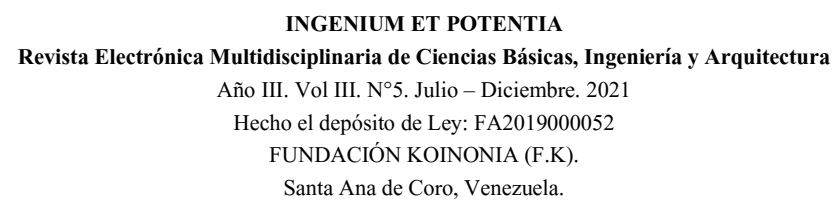

Sócrates Pedro Muñoz Pérez; Ramiro Stalin Coronel Camino; Julio César Vargas Villafuerte

\section{INTRODUCCIÓN}

El hormigón es un material de amplia uso en la construcción que tiene alta resistencia y adaptabilidad (V.M. Sounthararajan, Y Stalin Jose, \& ,S. Sivasankar , 2019), debido a sus buenas propiedades estructurales, de fácil fabricación y bajos costes; ante la creciente demanda de este producto se proponen alternativas ambientales que puedan ser ventajosas y económicas para ello es muy necesario desarrollar concreto con agregado no convencional (Sounthararajan, Sivasankar, Vinodh Kumar, Modak, \& Dilli Bai, 2019). Actualmente la ingeniería ha tenido un gran avance en el desarrollo de materiales de construcción, como en la tecnología para producirlos, donde busca obtener materiales más sostenibles y eficientes. En general, la actividad de construcción está en continua evolución que, a veces, se puede percibir lentamente, pero sin duda está en constante evolución (Huertas, Martinez, \& Espitia, 2019); ante ello la utilización de materiales alternativos es necesaria para lograr una producción de hormigón sostenible y duradera (Murugesan, Vidjeapriya, \& Bahurudee, 2020). El aumento de los costos de la energía fósil y las preocupaciones ambientales han dado lugar a nuevas oportunidades para la producción de materiales biodegradables basados en recursos naturales (Boontima , Noomhorm, Puttanlek, Uttapap, \& Rungsardthong, 2014) y uno de los mayores residuos agropecuarios del mundo es el bagazo de caña de azúcar que se obtiene a partir del proceso de trituración y extracción de su jugo, dicho material fibroso lo convierte en un ingrediente ideal (Y.R.Loh, D.Sujan, M.E.Rahman, \& C.A.Das, 2013) y debido a su densidad relativamente baja, su contenido alto de humedad, sus características morfológicas y las propiedades físico-mecánicas, es catalogado como un material adecuado para ser usado como Fibrorefuerzo (Hernández-Olivares, Medina-Alvarado, BurneoValdivieso, \& Zúñiga-Suárez, 2020; Osorio Saraz, Varón Aristizabal, \& Herrera Mejía, 2007). Las fibras vegetales son un tipo de compuestos renovables naturales que pueden satisfacer los requisitos de costo y resistencia; su estructura depende de la edad, el origen y las condiciones climaticas de la planta (Ruano et al., 2020). El bagazo de caña tambien al sufrir un proceso de calcinación en la industria azucarera, provoca residuos volátiles que han demostrado ser útiles en la construcción como adherente 


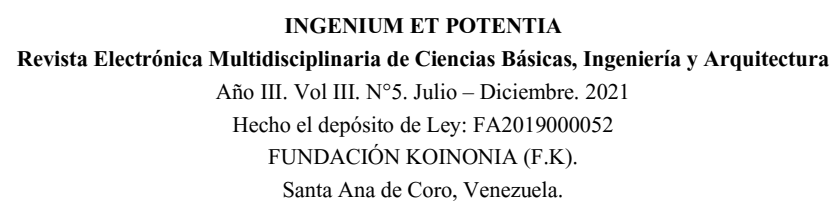

Sócrates Pedro Muñoz Pérez; Ramiro Stalin Coronel Camino; Julio César Vargas Villafuerte

puzolánico; la ceniza ha demostrado ser un buen componente puzolánico capaz de producir efectos en el comportamiento del concreto mejorando sus propiedades (Sajjad et al., 2017), pero la acción puzolánica obedece a la condición de combustión, relacionada con el proceso de calcinación (Duc, Yeong, \& My Ngoc, 2018). La existencia de estos residuos pueden ser empleados como agregados complementarios los cuales no necesitan ser tratados antes de ser usados en la mezcla de concretos o morteros (Cabrera-Madrid, Escalante-García, \& CastroBorges, 2016), Además, diversas investigaciones sobre la producción de morteros y concretos usando cenizas de bagazo de caña de azúcar como un material suplementario con propiedades cementosas (MCS) ya han demostrado ser un procedimiento eficiente, sin pérdida de resistencia a compresión de las muestras probadas (Berenguer et al., 2018). Además de la resistencia a la compresión y la tracción, la resistencia a la adherencia y trabajabilidad del hormigón es un factor importante para los criterios de diseño estructural (Nasir, Asma, Muhd, \& Hashem , 2016).

El presente trabajo se enfoca en la realización de una vasta revisión de literatura sobre el comportamiento de la mezcla de concreto al ser adicionado con desechos agrícolas como los derivados de la caña de azúcar y como estos influyen directamente en sus propiedades físicas mecánicas. 


\section{DESARROLLO}

\section{Características del bagazo de caña}

El bagazo de la caña, es el residuo pulposo seco que queda después de la extracción de jugo de caña de azúcar. (Xiong, 2018).

\section{Tabla 1.}

Composición Química del Bagazo, Fibra, corteza y pulpa.

\begin{tabular}{|l|l|l|l|l|}
\hline Compuestos & $\begin{array}{l}\text { Bagazo de caña } \\
\text { de azúcar en } \\
\text { crudo (\%) }\end{array}$ & Fibra (wt\%) & Núcleo (wt\%) & Pulpa (wt\%) \\
\hline Cell-soluble mater & 4.2 & 0.9 & 10.1 & - \\
\hline Hemicellulose & 28.5 & $20-30.8$ & 30.8 & - \\
\hline Cellulose & 50.4 & $30.3-59.7$ & 39.3 & 63.6 \\
\hline Lignin & 14.9 & $13-26$ & 15.3 & 5.95 \\
\hline Ash & 2.0 & $0.6-1.8$ & 3.2 & 0.75 \\
\hline Crud Protein & 1.59 & 1.31 & 1.85 & - \\
\hline
\end{tabular}

Fuente: Xiong (2018)

\section{Tabla 2.}

Resumen de las propiedades de la fibra de bagazo.

\begin{tabular}{|l|l|l|l|l|}
\hline Diámetro $(\mathrm{mm})$ & Densidad $(\mathrm{kg} / \mathrm{m3})$ & $\begin{array}{l}\text { Resistencia a la } \\
\text { Tensión (Mpa) }\end{array}$ & $\begin{array}{l}\text { Módulo de } \\
\text { Young 's (Mpa) }\end{array}$ & $\begin{array}{l}\text { Rotura Elástica } \\
(\%)\end{array}$ \\
\hline $0.3-0.5$ & $344-360$ & $70-107$ & 4500 & $3-7$ \\
\hline
\end{tabular}

Fuente: Xiong (2018)

\section{Ceniza de Bagazo de Caña}

Es un material de desecho no cohesivo que tiene una gravedad específica pequeña, relativamente más pequeña que la del suelo normal, y se comporta como material puzolánico (Tri Hatmoko \& Suryadharma, 2019) 


\section{Características Físicas}

La escoria de bagazo de caña de azúcar (CBCA) es un material que muestra buenas propiedades puzolánicas. Se obtiene al quemar entre 800 y $1000{ }^{\circ} \mathrm{C}$ durante $20 \mathrm{~min}$ el bagazo; dichas caracteristicas dependen de la técnica y eficacia de las centrales térmicas (Chindaprasirt, Sujumnongtokul, \& Posi, 2019) (Lorca Aranda, 2014).

\section{Tabla 3.}

Características Físicas de CBCA.

\begin{tabular}{|c|c|c|c|}
\hline Características Físicas & CBCA (como se recoge) & CBCA procesado & Norma relevante \\
\hline Gravedad específica & 1,91 & 2.12 & $\begin{array}{c}\text { IS4031-Parte } 11 \text { (BIS } \\
1988 b)\end{array}$ \\
\hline Superficie específica (Blaine) & $145 \mathrm{~m} 2 / \mathrm{kg}$ & $300 \mathrm{~m}^{2} / \mathrm{kg}$ & $\begin{array}{c}\text { ASTM C204-11 (ASTM } \\
2011 \mathrm{~b})\end{array}$ \\
\hline Pérdida por ignición & $21 \%$ & $6 \%$ & IS 1727 (BIS 2004) \\
\hline Consistencias & $50 \%$ & $40 \%$ & $\begin{array}{c}\text { IS } 4031 \text {,PARTE } 4 \text { (BIS } \\
2005)\end{array}$ \\
\hline Tiempo de fraguado inicial & 195 minutos & 190 minutos & $\begin{array}{c}\text { IS } 4031 \text {, Parte } 5 \text { (BIS } \\
1988 a)\end{array}$ \\
\hline Tiempo de fraguado terminal & $330 \mathrm{~min}$ & 285 minutos & $\begin{array}{l}\text { IS 4031, Parte } 5 \text { (BIS } \\
\text { 1988a) }\end{array}$ \\
\hline
\end{tabular}

Fuente: Deepika, Anand, Bahurudeen, \& Santhanam (2017)

\section{Características Químicas}

La escoria de bagazo crudo está compuesta principalmente de sílice (60-75\%), CaO, K2 O y otros óxidos menores, incluido Al2 O3 Fe2 O3 (Bahurudeen, Wani, Abdul Basit, \& Santhanam, 2016). 
Tabla 4.

Composición de óxido de CBCA según autores.

\begin{tabular}{|c|c|c|c|c|c|c|c|c|c|}
\hline $\mathbf{N}^{\circ}$ & Autor y Ciudad & $\mathrm{SiO2}$ & Fe2O3 & Al2O3 & $\mathrm{CaO}$ & MgO & $\begin{array}{l}\mathrm{SO} / \\
\mathrm{SO} 4\end{array}$ & K2O & LOI \\
\hline 1 & $\begin{array}{l}\text { (Abdolkarim } \\
\text { Abbasi \& Amin } \\
\text { Zargar, 2013) } \\
\text { (Iran) }\end{array}$ & 44.70 & 2.90 & 2.40 & 14.9 & 3.5 & N.A & 4.40 & 16.7 \\
\hline 2 & $\begin{array}{l}\text { (Abdulkadir, } \\
\text { T.S., Oyejobi, } \\
\text { D.O, \& Lawal, } \\
\text { A.A, 2014) } \\
\text { (Nigeria) }\end{array}$ & 72.85 & 6.96 & 1.08 & 9.97 & 6.49 & N.A & 6.77 & 4.23 \\
\hline 3 & $\begin{array}{l}\text { (Asma, } \\
\text { NasirShafiq, } \\
\text { MuhdFadhilNu } \\
\text { ruddin, \& } \\
\text { Fareed, 2014) } \\
\text { (Sudan) }\end{array}$ & 77.25 & 4.21 & 6.37 & 4.05 & 2.61 & 0.11 & 2.34 & 1.40 \\
\hline 4 & $\begin{array}{l}\text { (Otoko, } \\
\text { 2014)(Nigeria) }\end{array}$ & 41.15 & 2.70 & 7.00 & 3.20 & 0.12 & 0.03 & 8.75 & 17.7 \\
\hline 5 & $\begin{array}{l}\text { (Lathamahesw } \\
\text { ari, } \\
\text { Kalaiyarasan, } \\
\& \\
\text { Mohankumar, } \\
\text { 2017) }\end{array}$ & 67.82 & 2.56 & 6.33 & 1.54 & 2.03 & - & 2.87 & 2.31 \\
\hline
\end{tabular}




\begin{tabular}{|l|l|l|l|l|l|l|l|l|l|}
\hline 6 & $\begin{array}{l}\text { Flyash- F } \\
\text { (Mettur, India) }\end{array}$ & 54.40 & 11.32 & 25.60 & 2.03 & 0.92 & 1.70 & 0.73 & 1.32 \\
\hline 7 & Cement & 20.24 & 4.61 & 2.89 & 66.7 & 1.63 & 2.31 & 0.29 & 1.43 \\
\hline
\end{tabular}

Fuente: Deepika, Anand, Bahurudeen, \& Santhanam (2017),

\section{Utilización de la ceniza de bagazo de caña en el hormigón}

El uso de cenizas de bagazo como material de cementación suplementario ha sido un tema de gran interés para los investigadores desde hace mucho tiempo (Farnaz, Arjumend , \& Mehmood , 2019) y se puede utilizar como reemplazo de cemento en hormigón (Sajjad et al., 2017).

Ceniza de bagazo y sus efectos sobre las propiedades físico -mecánicos del hormigón.

\section{Materiales}

a. Cemento.

Para la preparación de un concreto y mortero con CBCA se usa generalmente cemento Portland ordinario (Sundaravadivel \& Mohana , 2018), de 53 grados conforme a IS: 12269-2009 y se utilizó en todas las mezclas. La gravedad específica y la finura de Blaine de las muestras de cemento son 3,15 y $370 \mathrm{~m} / \mathrm{kg}$, respectivamente (Manjunath \& Rahul, 2019)

\section{b. Agregado Fino}

Se utiliza arena fluvial disponible en la región con una gravedad específica de 2.613. Las fracciones de $4,75 \mathrm{~mm}$ a $150 \mu$ se denominan agregados finos, y la densidad a granel en estado suelto y estado rodado son $1550.463 \mathrm{~kg} / \mathrm{m}^{3}$ y $1699.945 \mathrm{~kg} / \mathrm{m}^{3}$ respectivamente. El porcentaje de absorción de agua es del 4,562\% (Lakshmi Priya \& Ragupathy, 2016) 


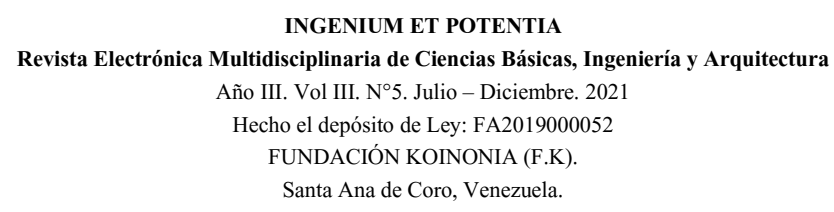

Sócrates Pedro Muñoz Pérez; Ramiro Stalin Coronel Camino; Julio César Vargas Villafuerte

\section{c. Agregado Grueso}

Se utilizan los agregados triturados de $20 \mathrm{~mm}$ de tamaño nominal de la fuente local y su gravedad específica es de 2,31. El volumen densidad en estado flojo y estado rodado son $1778.618 \mathrm{~kg} / \mathrm{m} 3$ y $1907.981 \mathrm{~kg} / \mathrm{m} 3$ respectivamente. El porcentaje de absorción de agua es del 0,217\% (Lakshmi Priya \& Ragupathy, 2016)

\section{d. Súper plastificante}

Los súper plastificantes o los reductores de agua de alto rango son aditivos químicos utilizados donde se requiere una suspensión de partículas bien dispersas. Eso se puede agregar a las mezclas de concreto para mejorar la trabajabilidad, reducir la relación agua-cemento y reducir el contenido de cemento. Los reductores de agua típicos reducen el contenido de agua en aproximadamente un 5-10\%. (Sundaravadivel \& Mohana , 2018)

Se usó un superplastificante a base de policarboxilato como agente reductor de agua en mezclas SCC. Está libre de cloruros y tiene una densidad de $1.09 \mathrm{~g} / \mathrm{cm} 3$ (Duc, Yeong, \& My Ngoc, 2018)

\section{e. Ceniza de Bagazo de caña de azúcar(CBCA)}

La ceniza adquirida se obtuvo en la Máquina de abrasión de Los Ángeles en el momento en que la cantidad retenida en el tamiz de $45 \mathrm{~mm}$ era inferior al 5\% (Nasir, Asma, Muhd, \& Hashem , 2016)

Aquí, el procesamiento de ceniza de bagazo implica (i) incineración de ceniza de bagazo cruda en $600^{\circ} \mathrm{C}$ durante $2 \mathrm{~h}$, y (ii) la molienda de cenizas gruesas de bagazo son transformados en molinos de bolas a una velocidad de $40 \mathrm{rpm}$ durante $120 \mathrm{~min}$ que disminuye el tamaño de las partículas y aumenta la finura y la actividad puzolánica de la ceniza (Bayapureddy, Muniraj, \& Gangireddy Mutukuru, 2020). 


\section{Propiedades del hormigón con CBCA}

Para esta sección se realizó un compendio de documentos de investigaciones contenidas en la literatura a partir del año 2007, poniendo atención en los niveles de reemplazo del cemento portland por escoria de alto horno generados a partir de la caña de azúcar y el efecto causado en las propiedades físico-mecánicas del concreto endurecido a las edades de 28 días. Se pudo analizar a partir de un sondeo bibliográfico de aproximadamente 14 artículos donde la CBCA se utilizó como método de reemplazo parcial en el hormigón apoyado en los diferentes sistemas de procesamiento. 
Santa Ana de Coro, Venct

Sócrates Pedro Muñoz Pérez; Ramiro Stalin Coronel Camino; Julio César Vargas Villafuerte

Tabla 5.

Comparación de varios trabajos de investigación publicados entre el 2007 y 2020.

\begin{tabular}{|c|c|c|c|c|c|c|c|}
\hline $\begin{array}{l}\text { Equipo de } \\
\text { investigación/ } \\
\text { Autor }\end{array}$ & $\begin{array}{l}\text { Métodos } \\
\text { /Proceso }\end{array}$ & $\begin{array}{l}\text { Proporción de } \\
\text { Mezcla }\end{array}$ & Trabajabilidad & $\begin{array}{l}\text { Resistencia a la } \\
\text { compresión f'c }\end{array}$ & Resistencia a la Flexión & $\begin{array}{l}\text { Ciudad de } \\
\text { Estudio }\end{array}$ & $\begin{array}{l}\text { Año de } \\
\text { Publicac } \\
\text { ión }\end{array}$ \\
\hline $\begin{array}{l}\text { (K. Ganesan, } \\
\text { K. Rajagopal, } \\
\& \quad \text { K. } \\
\text { Thangavel, } \\
\text { 2007) }\end{array}$ & $\begin{array}{l}\text { Quemado } \\
\text { a } \\
\text { temperatu } \\
\text { ra } \\
\text { controlada } \\
\text { a } 650 \quad \mathrm{C} \\
\text { durante } \\
\text { una hora. }\end{array}$ & $\begin{array}{l}\mathrm{M0}(\mathrm{a} / \mathrm{c}) \mathrm{y} \\
\mathrm{M}(\mathrm{a} / \mathrm{c}+\mathrm{cbca}) \\
\text { mezclas con una } \\
\text { relación de } 0.53\end{array}$ & $\begin{array}{l}\text { Mezcla con el } 10 \% \text { de } \\
\text { reemplazo mejoro la } \\
\text { trabajabilidad } \\
(115 \mathrm{~mm}) \text { a } \\
\text { comparación de la } \\
\text { mezcla patrón } \\
(98 \mathrm{~mm})\end{array}$ & $\begin{array}{l}\text { Mezcla con el } 10 \% \\
\text { de reemplazo } \\
\text { mejoro en un } 17 \% \\
\text { la resistencia a la } \\
\text { compresión ( } 33.86 \\
\text { N/mm2)a } 28 \text { días }\end{array}$ & $\begin{array}{l}\text { El valor de resistencia a la } \\
\text { tracción se da con el } 20 \% \text { de } \\
\text { CBCA siendo el límite } \\
\text { óptimo. Con referencia a la } \\
\text { resistencia a sulfatos las } \\
\text { adherencia disminuye en } \\
\text { comparación con la mezcla } \\
\text { patrón }\end{array}$ & India & 2007 \\
\hline $\begin{array}{l}\text { (G.C. Cordeiro, } \\
\text { R.D. Toledo } \\
\text { Filho, L.M. } \\
\text { Tavares, \& } \\
\text { E.M.R. }\end{array}$ & $\begin{array}{l}\text { Quemado } \\
\text { entre } \\
700^{\circ} \mathrm{C} \text { y } \\
900^{\circ} \mathrm{C}, \text { Moli } \\
\text { enda } \\
\text { usando }\end{array}$ & $\begin{array}{l}\text { Las mezclas se } \\
\text { elaboraron con } \\
\text { cenizas de tamaños } \\
\text { de partículas, con } \\
\text { valores D50 que van } \\
\text { desde } 1,65 \mu \mathrm{m} \text { a }\end{array}$ & $\begin{array}{l}\text { El mortero CBCA de } \\
\text { hormigón } \\
\text { proporciona la mayor } \\
\text { resistencia a la } \\
\text { compresión }\end{array}$ & - & - & Brasil & 2008 \\
\hline
\end{tabular}


Hecho el depósito de Ley: FA2019000052

UUNDACION KOINONIA (F.K).

Sócrates Pedro Muñoz Pérez; Ramiro Stalin Coronel Camino; Julio César Vargas Villafuerte

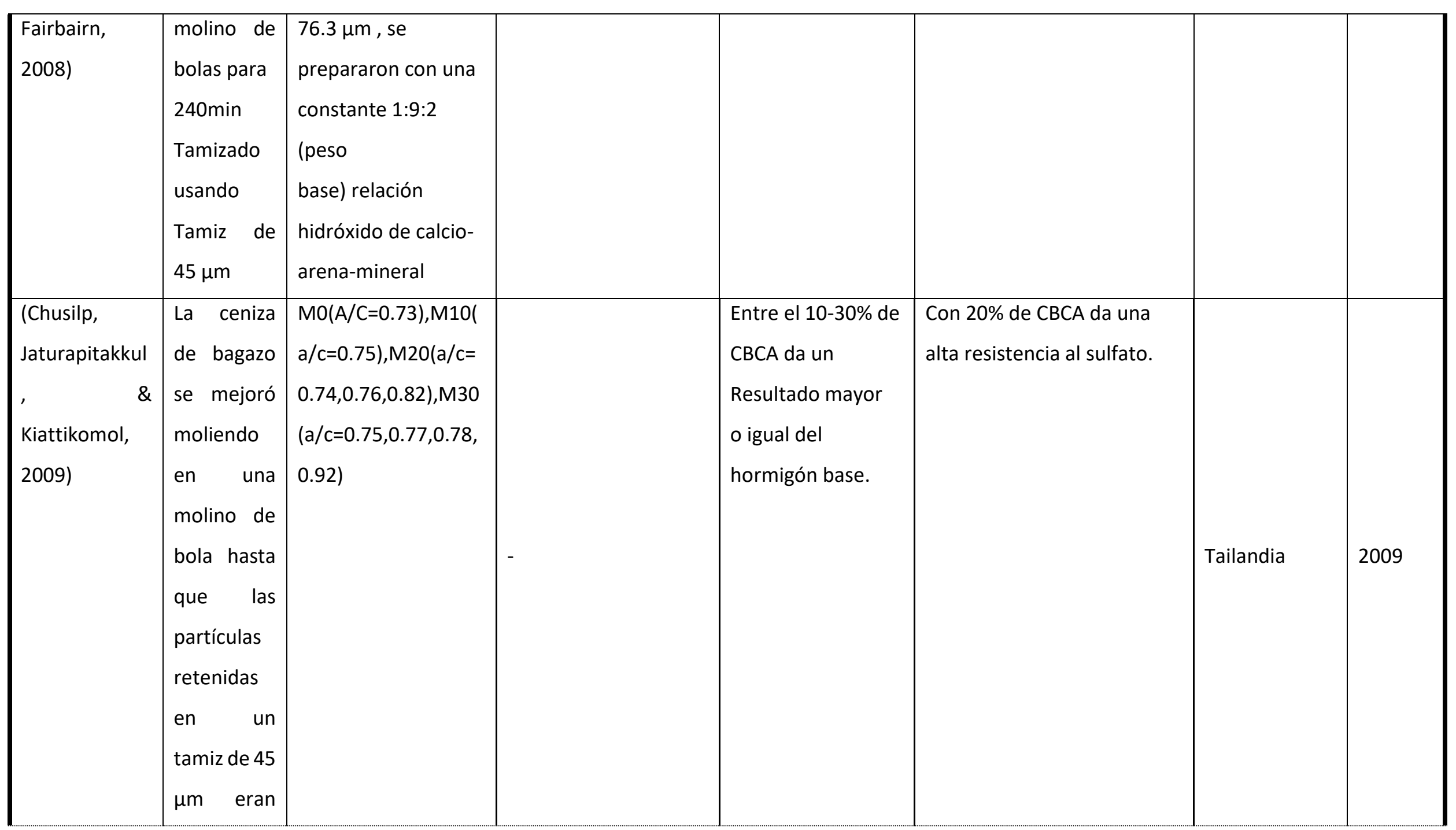


FUNDACIÓN KOINONIA (F.K).

Sócrates Pedro Muñoz Pérez; Ramiro Stalin Coronel Camino; Julio César Vargas Villafuerte

\begin{tabular}{|c|c|c|c|c|c|c|c|}
\hline & $\begin{array}{l}\text { inferiores } \\
\text { al } 5 \% \text { y fue } \\
\text { entonces } \\
\text { poner en } \\
\text { un horno a } \\
550 \quad C \\
\text { durante } \\
\text { unos } 45 \\
\text { min. }\end{array}$ & & & & & & \\
\hline $\begin{array}{l}\text { (Sales \& Lima, } \\
\text { 2010) }\end{array}$ & $\begin{array}{l}\text { la } \\
\text { caracteriza } \\
\text { ción } \\
\text { se secó al } \\
\text { horno a } \\
100 \text { oC } \\
\text { durante } 12 \\
\text { h y molió } \\
\text { durante } 3 \\
\text { min en }\end{array}$ & $\begin{array}{l}\text { Se usó para todas las } \\
\text { mezclas una relación } \\
\text { a/c de } 0.55\end{array}$ & $\begin{array}{l}\text { Con cemento } \\
\text { Portland de alta } \\
\text { resistencia temprana } \\
\text { resistencia al } \\
\text { sulfato(CV) mejora la } \\
\text { trabajabilidad } \\
\text { reemplazando en } 50 \% \\
\text {,cemento de escoria } \\
\text { de alto horno(CIII) se } \\
\text { produce una } \\
\text { disminución }\end{array}$ & $\begin{array}{l}\text { Con cemento } \\
\text { Portland de alta } \\
\text { resistencia } \\
\text { temprana } \\
\text { resistencia al } \\
\text { sulfato(CV) } \\
\text { disminuye la } \\
\text { resistencia a la } \\
\text { compresión } \\
\text {,cemento de } \\
\text { escoria de alto }\end{array}$ & $\begin{array}{l}\text { Para CV la tracción } \\
\text { disminuye adicionando } \\
\text { escorias pero el módulo de } \\
\text { elasticidad aumenta, para } \\
\text { CIII la tracción mejora al } \\
\text { reemplazar en } 50 \% \text { al igual } \\
\text { que el Modulo de } \\
\text { Elasticidad, para la ClI } \\
\text { mejora para un } 50 \% \text { de } \\
\text { reemplazo en cambio para } \\
\text { el módulo de elasticidad }\end{array}$ & Brasil & 2010 \\
\hline
\end{tabular}


Hecho el depósito de Ley: FA2019000052

FUNDACIÓN KOINONIA (F.K).

Sócrates Pedro Muñoz Pérez; Ramiro Stalin Coronel Camino; Julio César Vargas Villafuerte

\begin{tabular}{|c|c|c|c|c|c|c|c|}
\hline & $\begin{array}{l}\text { un molino } \\
\text { mecánico }\end{array}$ & & $\begin{array}{l}\text { (cemento Portland } \\
\text { modificado por la } \\
\text { escoria(CII) presenta } \\
\text { un aumento para un } \\
\text { reemplazo de } 30 \%\end{array}$ & $\begin{array}{l}\text { horno(CIII) se } \\
\text { produce una } \\
\text { disminución } \\
\text { y para cemento } \\
\text { Portland } \\
\text { modificado por la } \\
\text { escoria(CII) } \\
\text { presenta un } \\
\text { aumento para un } \\
\text { reemplazo de } 50 \%\end{array}$ & $\begin{array}{l}\text { mejora al } 30 \% \text { de } \\
\text { sustitución }\end{array}$ & & \\
\hline (Amin, 2011) & $\begin{array}{l}\text { quemado a } \\
650^{\circ} \mathrm{C} \\
\text { durante } 1 \mathrm{~h}\end{array}$ & $\begin{array}{l}\text { Para todas las } \\
\text { mezclas relación a/c } \\
\approx 0.45\end{array}$ & - & $\begin{array}{l}\text { El reemplazo entre } \\
\text { el } 5 \% \text { y el } 15 \% \\
\text { mejora la } \\
\text { resistencia a } \\
\text { compresión }\end{array}$ & $\begin{array}{l}\text { Mejora la resistencia a la } \\
\text { tensión para valores entre el } \\
5 \% \text { y } 15 \% \text { de reemplazo } \\
\text {,Presenta una resistencia } \\
\text { apreciable a la } \\
\text { permeabilidad y difusión del } \\
\text { cloruro }\end{array}$ & Pakistán & 2011 \\
\hline
\end{tabular}


FUNDACIÓN KOINONIA (F.K)

Sócrates Pedro Muñoz Pérez; Ramiro Stalin Coronel Camino; Julio César Vargas Villafuerte

\begin{tabular}{|c|c|c|c|c|c|c|c|}
\hline $\begin{array}{l}\text { (Somna , } \\
\text { Jaturapitakkul } \\
\text {, Rattanachu, } \\
\text { \& Chalee , } \\
\text { 2012) }\end{array}$ & $\begin{array}{l}\text { Tamizado } \\
\text { usando } \\
\text { Tamiz de } \\
45 \mu \mathrm{m}\end{array}$ & $\begin{array}{l}\text { Se tomó una } \\
\text { relación a/c } \approx 0.45 \\
\text { constante para } \\
\text { todas las mezclas, se } \\
\text { añadió súper } \\
\text { plastificante para } \\
\text { mezclas que } \\
\text { contienen } \\
\text { reemplazo } \\
\text { porcentual }\end{array}$ & $\begin{array}{l}\text { Presentan un Slump } \\
\text { entre } 60 \text { y } 80 \text { mm a } \\
\text { comparación de la } \\
\text { muestra control(70 } \\
\text { mm) }\end{array}$ & $\begin{array}{l}\text { 20\% de CBCA da } \\
\text { una mayor } \\
\text { resistencia a la } \\
\text { compresión y } \\
\text { módulo de } \\
\text { elasticidad. }\end{array}$ & $\begin{array}{l}\text { Del } 20-35 \% \text { del CBCA } \\
\text { mejora la permeabilidad al } \\
\text { agua } \\
\text { Hasta el } 50 \% \text { del CBCA da } \\
\text { resistencia al cloruro }\end{array}$ & Tailandia & 2012 \\
\hline $\begin{array}{l}\text { (Montakarnti } \\
\text { wong, Chusilp, } \\
\text { Tangchirapat, } \\
\& \\
\text { Jaturapitakkul } \\
\text {,2013) }\end{array}$ & $\begin{array}{l}\text { Quemado } \\
\text { a una } \\
\text { temperatu } \\
\text { ra entre } \\
800^{\circ} \mathrm{C} \text { y } \\
100^{\circ} \mathrm{C} \text {, La } \\
\text { ceniza de } \\
\text { bagazo se } \\
\text { mejoró } \\
\text { moliendo }\end{array}$ & $\begin{array}{l}\text { Se tomó una } \\
\text { relación a/c } \approx 0.45 \\
\text { constante para } \\
\text { todas las mezclas, se } \\
\text { añadió súper } \\
\text { plastificante para } \\
\text { mezclas que } \\
\text { contienen } \\
\text { reemplazo } \\
\text { porcentual, además }\end{array}$ & $\begin{array}{l}\text { para las muestras } O B \\
\text { el Slump oscila entre } \\
60 \text { y } 100 \mathrm{~mm} \text {,en } \\
\text { cambio para las GB su } \\
\text { Slump varía entre } 60 \\
\text { mm y } 75 \text { mm en } \\
\text { comparación de las } \\
\text { muestras normales }\end{array}$ & $\begin{array}{l}\text { La resistencia a la } \\
\text { compresión se ve } \\
\text { afectada en } \\
\text { referencia a la } \\
\text { mezcla patrón y } \\
\text { disminuye tanto } \\
\text { para las mezclas } \\
\text { con OB y para la } \\
\text { GB aumenta la } \\
\text { resistencia al }\end{array}$ & - & Tailandia & 2013 \\
\hline
\end{tabular}


Hecho el depósito de Ley: FA2019000052

FUNDACIÓN KOINONIA (F.K).

Sócrates Pedro Muñoz Pérez; Ramiro Stalin Coronel Camino; Julio César Vargas Villafuerte

\begin{tabular}{|c|c|c|c|c|c|c|c|}
\hline & $\begin{array}{l}\text { en una } \\
\text { molino de } \\
\text { bola hasta } \\
\text { que las } \\
\text { partículas } \\
\text { retenidas } \\
\text { en un } \\
\text { tamiz de } 45 \\
\mu m \quad \text { eran } \\
\text { inferiores } \\
\text { al } 5 \%\end{array}$ & $\begin{array}{l}\text { se realizaron con } \\
\text { muestras directas de } \\
\text { la industria (OB)y } \\
\text { otras molidas(GB) }\end{array}$ & & $\begin{array}{l}\text { adherir el } 20 \% \text { de } \\
\text { reemplazo }\end{array}$ & & & \\
\hline $\begin{array}{l}\text { (K.Rekha \& } \\
\text { R.Thenmozhi, } \\
\text { 2014) }\end{array}$ & $\begin{array}{l}\text { Quemado } \\
\text { a } 700{ }^{\circ} \mathrm{C} \\
\text { por una } \\
\text { hora }\end{array}$ & $\mathrm{M}(1: 1.5: 3)$ & $\begin{array}{l}\text { la sustitución del 5\% } \\
\text { de CBCA se considera } \\
\text { un nivel óptimo de } \\
\text { tener una capacidad } \\
\text { de trabajo adecuada }\end{array}$ & $\begin{array}{l}\text { Para la sustitución } \\
\text { del } 5 \% \text { de CBCA } \\
\text { por cemento, las } \\
\text { características } \\
\text { aumenta en un } \\
30 \%\end{array}$ & $\begin{array}{l}\text { Para la sustitución del } 5 \% \\
\text { aumenta en un } 10 \% \text { en } \\
\text { resistencia a la tensión, Para } \\
\text { la sustitución del } 5 \% \\
\text { aumenta en un } 8 \% \text { en } \\
\text { resistencia a la Flexión. }\end{array}$ & India & 2014 \\
\hline
\end{tabular}


FUNDACIÓN KOINONIA (F.K)

Sócrates Pedro Muñoz Pérez; Ramiro Stalin Coronel Camino; Julio César Vargas Villafuerte

\begin{tabular}{|c|c|c|c|c|c|c|c|}
\hline $\begin{array}{l}\text { (Almeida, } \\
\text { Sales, Moretti } \\
\text { \& Mendes, } \\
\text { 2015) }\end{array}$ & $\begin{array}{l}\text { Quemado } \\
\text { a } 700{ }^{\circ} \mathrm{C} \\
\text { para } \\
\text { 3h } \\
\text { Tamizado } \\
\text { usando } \\
\text { Tamiz de } \\
90 \mu \mathrm{m}\end{array}$ & $\begin{array}{l}\text { Para la mezcla } \\
\text { patrón (M0)se usó } \\
\text { una relación a/c } \\
\approx 0.42 \text {,para mezcla } \\
\text { con } 30 \% \text { de } \\
\text { reemplazo(M30) a } \\
\text { una a/c } \approx 0.44 \text { y para } \\
\text { la mezcla con } 50 \% \\
\text { de reemplazo(M50) } \\
\text { una relación de a/c } \\
\approx 0.47\end{array}$ & $\begin{array}{l}\text { Las M0 obtuvieron } \\
250 \pm 10 \text {, para los M30 } \\
\text { obtuvieron } 251 \pm 10 \text { y } \\
\text { para los M } 50 \\
\approx 258 \pm 10\end{array}$ & $\begin{array}{l}\text { 15-20\% de CBCA } \\
\text { alcanzado } \\
\text { Mayor resistencia } \\
\text { a la compresión en } \\
\text { etapas posteriores }\end{array}$ & $\begin{array}{l}15-20 \% \text { de CBCA disminuye } \\
\text { la } \\
\text { porosidad y alcalinidad del } \\
\text { mortero }\end{array}$ & Brasil & 2015 \\
\hline
\end{tabular}


FUNDACIÓN KOINONIA (F.K).

Sócrates Pedro Muñoz Pérez; Ramiro Stalin Coronel Camino; Julio César Vargas Villafuerte

\begin{tabular}{|c|c|c|c|c|c|c|}
\hline & $\begin{array}{l}\text { el } \\
\text { momento } \\
\text { en que la } \\
\text { cantidad } \\
\text { retenida } \\
\text { en el tamiz } \\
\text { de } 45-\mu / m \\
\text { era inferior } \\
\text { al } 5 \% \text {. }\end{array}$ & & & $\begin{array}{l}\text { entre el } 35 \text { y el } \\
50 \% \text { de contenido } \\
\text { del SCBA mostró } \\
\text { mayor resistencia } \\
\text { a } 28 \text { y } 90 \text { d. }\end{array}$ & & \\
\hline $\begin{array}{l}\text { (Sajjad , y } \\
\text { otros, 2017) }\end{array}$ & $\begin{array}{l}\text { Pasa Tamiz } \\
300 \mu \mathrm{m}\end{array}$ & $\begin{array}{l}\text { M20 (1:1 1/2:3) } \\
\text { M15 (1:2:4) }\end{array}$ & $\begin{array}{l}\text { M20: con } 5 \% \text { de } \\
\text { reemplazo aumenta } \\
\text { entre } 15 \% \text { y con } 10 \% \\
\text { de adherencia } \\
\text { aumenta en un } 28 \% \text {. } \\
\text { M15: con } 5 \% \text { de } \\
\text { reemplazo aumenta } \\
\text { entre } 34 \% \text { y con } 10 \% \\
\text { de adherencia } \\
\text { aumenta en un } 45 \%\end{array}$ & $\begin{array}{l}\text { M20: Con } 5 \% \text { de } \\
\text { reemplazo de } \\
\text { cemento es el } \\
\text { porcentaje óptimo } \\
\text { produce } 28.50 \\
\mathrm{~N} / \mathrm{mm} 2 \text { en } \\
\text { promedio. } \\
\text { M15: Con } 5 \% \text { de } \\
\text { reemplazo de } \\
\text { cemento es el }\end{array}$ & 更 & 2017 \\
\hline
\end{tabular}


Hecho el depósito de Ley: FA2019000052

UUNDACIÓN KOINONIA (F.K).

Sócrates Pedro Muñoz Pérez; Ramiro Stalin Coronel Camino; Julio César Vargas Villafuerte

\begin{tabular}{|c|c|c|c|c|c|c|c|}
\hline & & & & $\begin{array}{l}\text { porcentaje óptimo } \\
\text { produce } 26.775 \\
\text { N/mm2 en } \\
\text { promedio. }\end{array}$ & & & \\
\hline $\begin{array}{l}\text { (Rajasekar, } \\
\text { Arunachalam, } \\
\text { Kottaisamy, \& } \\
\text { Saraswathy, } \\
\text { 2018) }\end{array}$ & $\begin{array}{l}\text { ceniza fue } \\
\text { incinerada } \\
\text { bajo } \\
\text { condicione } \\
\text { s } \\
\text { controlada } \\
\text { s en el } \\
\text { horno } \\
\text { para } \\
\text { diferentes } \\
\text { temperatu } \\
\text { ras entre }\end{array}$ & $\begin{array}{l}\text { Relación } \\
\text { agua/cemento de } \\
0.18\end{array}$ & $\begin{array}{l}\text { Reemplazo del } 5 \% \text {, la } \\
\text { capacidad de trabajo } \\
\text { estaba a la par con la } \\
\text { mezcla de control. }\end{array}$ & $\begin{array}{l}\text { Para el } 10 \% \text {, el } \\
15 \% \text { y el } 20 \% \text {, } \\
\text { hubo un } \\
\text { considerable } \\
\text { aumento de la } \\
\text { resistencia en } \\
\text { comparación con } \\
\text { el hormigón de } \\
\text { control. } \\
\text { La mejora de la } \\
\text { resistencia a la } \\
\text { compresión está }\end{array}$ & $\begin{array}{l}\text { Reduce la penetración de } \\
\text { iones de cloruro al } \\
\text { sustituirlo porcentualmente }\end{array}$ & (3) & 2018 \\
\hline
\end{tabular}


FUNDACIÓN KOINONIA (F.K)

Sócrates Pedro Muñoz Pérez; Ramiro Stalin Coronel Camino; Julio César Vargas Villafuerte

\begin{tabular}{|c|c|c|c|c|c|c|c|}
\hline & $\begin{array}{l}450{ }^{\circ} \mathrm{C} \mathrm{y} \\
650^{\circ} \mathrm{C} \text { con } \\
\text { Variación } \\
\text { de } 50^{\circ} \mathrm{C}\end{array}$ & & & $\begin{array}{l}\text { entre el } 0,4 \% \text { y el } \\
13,5 \%\end{array}$ & & & \\
\hline $\begin{array}{l}\text { (Manjunath \& } \\
\text { Rahul, 2019) }\end{array}$ & $\begin{array}{l}\text { se usó } \\
\text { cemento } \\
\text { Portland } \\
\text { ordinario } \\
\text { de } 53 \\
\text { grados } \\
\text { (OPC) }\end{array}$ & $\begin{array}{l}\text { Se desarrollaron un } \\
\text { total de } 12 \text { mezclas } \\
\text { de concreto SCC } \\
\text { basadas en CBCA con } \\
\text { OPC como el } \\
\text { principal aglutinante } \\
\text { en el rango de } 450- \\
500 \text { kg / m3 con } \\
\text { niveles de reemplazo } \\
\text { de CBCA en } 10,20, \\
30 \quad y \quad 40 \% \text { en } \\
\text { consideración. Todas } \\
\text { las mezclas tenían } \\
\text { una relación }\end{array}$ & $\begin{array}{l}\text { Muestran un } \\
\text { comportamiento } \\
\text { mejorado en términos } \\
\text { de fluidez. }\end{array}$ & $\begin{array}{l}\text { En contenidos } \\
\text { superiores al } 20 \% \\
\text { ha llevado a un } \\
\text { rendimiento de } \\
\text { resistencia a la } \\
\text { compresión } \\
\text { disminuido, Las } \\
\text { mezclas } \\
\text { desarrolladas } \\
\text { mostraron valores } \\
\text { de resistencia a la } \\
\text { compresión que } \\
\text { oscilan entre } 40 \text { y } \\
55.8 \text { MPa }\end{array}$ & $\begin{array}{l}\text { en contenidos superiores al } \\
20 \% \text { ha llevado a un } \\
\text { rendimiento de resistencia a } \\
\text { la tensión disminuido, } \\
\text { valores de resistencia a la } \\
\text { tensión de división entre } 3 \\
\text { y4.5 MPa a la edad de } 28 \text { días } \\
\text { sin afectar las propiedades } \\
\text { de fluidez, con un reemplazo } \\
\text { óptimo del CBCA de } 20 \% \text {. La } \\
\text { absorción de agua de todas } \\
\text { las mezclas de prueba } \\
\text { también es satisfactoria, con }\end{array}$ & India & 2019 \\
\hline
\end{tabular}


Hecho el depósito de Ley: FA2019000052

FUNDACIÓN KOINONIA (F.K).

Sócrates Pedro Muñoz Pérez; Ramiro Stalin Coronel Camino; Julio César Vargas Villafuerte

\begin{tabular}{|c|c|c|c|c|c|c|c|}
\hline & & $\begin{array}{l}\text { constante w / b de } \\
0,45 \text { con un } 2.5 \% \text { de } \\
\text { súper plastificante. }\end{array}$ & & & $\begin{array}{l}\text { valores que oscilan entre un } \\
\text { bajo } 3-4 \% \text {. }\end{array}$ & & \\
\hline $\begin{array}{l}\text { (Andrade } \\
\text { Neto , Santos } \\
\text { de França, } \\
\text { Santana de } \\
\text { Amorim } \\
\text { Júnior, \& } \\
\text { Véras Ribeiro, } \\
\text { 2020) }\end{array}$ & $\begin{array}{l}\text { La CBCA } \\
\text { fue } \\
\text { calcinada a } \\
600^{\circ} \text { C, } \\
\text { tiene una } \\
\text { alta } \\
\text { actividad } \\
\text { puzolánica } \\
\text { debido a } \\
\text { la } \\
\text { presencia } \\
\text { de sílice }\end{array}$ & $\begin{array}{l}\text { La relación agua- } \\
\text { cemento }(\mathrm{a} / \mathrm{c}) \text { se } \\
\text { estableció como } \\
0,53 \text { y se definió } \\
\text { después de corregir } \\
\text { el valor de desplome } \\
\text { para el hormigón de } \\
\text { referencia }\end{array}$ & $\begin{array}{l}\text { La menor } \\
\text { trabajabilidad del } \\
\text { hormigón son las que } \\
\text { contiene CBCA podría } \\
\text { generar más vacíos } \\
\text { durante el moldeo de } \\
\text { los especímenes, por } \\
\text { lo cual resultaría en } \\
\text { una mayor porosidad } \\
\text { en el estado } \\
\text { endurecido, el } \\
\text { disminuyendo }\end{array}$ & $\begin{array}{l}\text { La adición de hasta } \\
\text { un 15\% de CBCA } \\
\text { dio lugar a } \\
\text { reducciones en la } \\
\text { porosidad y } \\
\text { absorción la } \\
\text { mejoras en debido } \\
\text { resistencia, dísico, } \\
\text { al efecto y } \\
\text { mejor embalaje, y } \\
\text { la reacción } \\
\text { puzolánica }\end{array}$ & $\begin{array}{l}\text { La adición de CBCA dio lugar } \\
\text { a una vida útil más alta } \\
\text { contra la penetración de } \\
\text { iones de cloro. }\end{array}$ & Brasil & $\begin{array}{l}2020(20 \\
21)\end{array}$ \\
\hline
\end{tabular}


Revista Electrónica Multidisciplinaria de Ciencias Básicas, Ingeniería y Arquitectura

Año III. Vol III. N ${ }^{\circ}$. Julio - Diciembre. 202

Hecho el depósito de Ley: FA2019000052

FUNDACIÓN KOINONIA (F.K)

Santa Ana de Coro, Venezuela.

Sócrates Pedro Muñoz Pérez; Ramiro Stalin Coronel Camino; Julio César Vargas Villafuerte

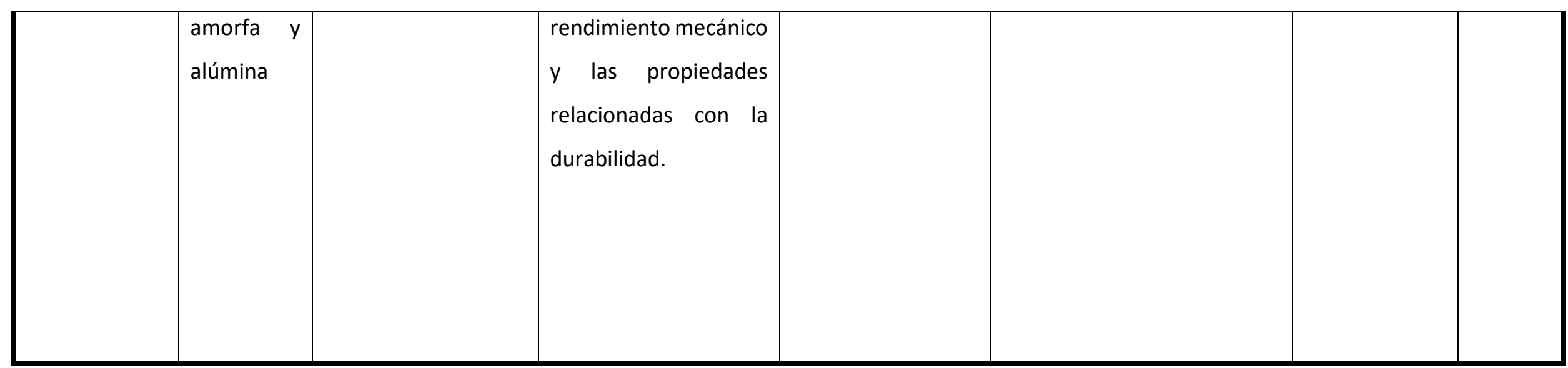


Para las mezclas anteriormente mencionadas se usó cemento portland y escoria. Normalmente la cantidad de agua usada para elaborar la mezcla de hormigón está especificada de forma implícita en la relación agua/cemento (a/c), Sin embargo existen casos particulares donde no se usa únicamente agua para la preparación de la mezcla sino que se requiere de alguna solución activadora de algún subproducto, entonces el término empleado es $\mathrm{s} / \mathrm{mc}$ que representa la solución acuosa con el agente químico (solución alcalina) y material cementante. La resistencia a la compresión del hormigón en función de la densidad de concreto permite comparar la densidad de hormigón mezclado a distintas edades observar que donde existe una relación directa, donde a mayor densidad produce mayor resistencia a la compresión (Jagadesh, Ramachandramurthy, \& Murugesan, 2018)

\section{Fibra de bagazo y su efecto en las propiedades Físico-Mecánicos del hormigón}

Cuando se aplican las modificaciones y los procedimientos de fabricación apropiados, el SCB muestra propiedades mecánicas mejoradas tales como la resistencia a la tracción, resistencia a la flexión, módulo de flexión, dureza, y resistencia al impacto (Loh, Sujan, Rahman, \& Das, 2013)

Para el bagazo crudo, se sumerge en agua a $30^{\circ} \mathrm{C}$ durante $30 \mathrm{~min}$. y luego se seca al aire libre durante 14 días. La intención de este proceso era reducir el residuo contenido de azúcar del bagazo y eliminar las impurezas (Ribeiro, Yamamoto, \& Yamashiki, 2020); posteriormente, se tamiza el bagazo crudo. Las fibras de bagazo (BF) del estudio pasaron por un tamiz de $4,76 \mathrm{~mm}$ y permanecieron en un Tamiz de 2 $\mathrm{mm}$ con una variación de longitud entre $8 \mathrm{~mm}$ y $44 \mathrm{~mm}$ (Ribeiro, Yamamoto, \& Yamashiki, 2020) 
Tabla 6.

Investigaciones realizadas referentes a la fibra de Bagazo de caña.

\begin{tabular}{|c|c|c|c|c|c|c|c|}
\hline $\begin{array}{l}\text { Equipo de } \\
\text { investigació } \\
n \\
\text { n/Autor }\end{array}$ & Método/ Proceso & $\begin{array}{l}\text { Propor } \\
\text { ción de } \\
\text { la } \\
\text { mezcla }\end{array}$ & Trabajabilidad & $\begin{array}{l}\text { Resistencia a la compresión } \\
f^{\prime} c\end{array}$ & Resistencia a la Flexión & $\begin{array}{l}\text { Ciudad de } \\
\text { estudio }\end{array}$ & $\begin{array}{l}\text { Año de } \\
\text { publicaci } \\
\text { ón }\end{array}$ \\
\hline $\begin{array}{l}\text { (Loh, Sujan, } \\
\text { Rahman, \& } \\
\text { Das, 2013) }\end{array}$ & $\begin{array}{l}\text { Las fibras de bagazo } \\
\text { fueron inmersas en } \\
\text { Hidróxido de calcio al 5,0 } \\
\text { \% durante } 24 \text { horas a una } \\
\text { temperatura de } \\
\text { laboratorio de } 24^{\circ} \mathrm{C} \text {, para } \\
\text { darle una protección del } \\
\text { medio alcalino de la } \\
\text { Pasta de cemento. } \\
\text { Final mente se obtienen } \\
\text { nos fibras ,una del } \\
\text { tamaño del tamiz №4 y el } \\
\text { otro № } 6\end{array}$ & $\begin{array}{l}\mathrm{M}(\mathrm{P}) \\
\mathrm{M}+0.5 \\
\% \mathrm{AG} \\
\mathrm{M}+2.5 \\
\% \mathrm{AG} \\
\mathrm{M}+5 \% \mathrm{~A} \\
\mathrm{G})\end{array}$ & - & $\begin{array}{l}\text { Para la muestra patrón es de } \\
15.7 \mathrm{MPa} \text {; para las muestras } \\
\text { con fibra que pasa el tamiz №4 } \\
\text { en proporciones de reemplazo } \\
\text { del } 0.5 \%, 2.5 \% \text { y } 5 \% \text { fueron } \\
13.43,4.92 \text { y } 1.65 \text { MPa } \\
\text { respectivamente. Asimismo } \\
16.88,8.6,2.42 \mathrm{MPa} \text { para las } \\
\text { muestras con fibras que pasan } \\
\text { el tamiz №6 }\end{array}$ & - & Medellín & 2007 \\
\hline
\end{tabular}


Sócrates Pedro Muñoz Pérez; Ramiro Stalin Coronel Camino; Julio César Vargas Villafuerte

\begin{tabular}{|c|c|c|c|c|c|c|c|}
\hline $\begin{array}{l}\text { (Osorio } \\
\text { Saraz, Varón } \\
\text { Aristizabal, } \\
\text { \& Herrera } \\
\text { Mejía, 2007) }\end{array}$ & $\begin{array}{l}\text { Se lavó y secó la fibra, } \\
\text { posteriormente se } \\
\text { procedió a cortarlas con } \\
\text { longitud de } 15 \mathrm{~mm} \text { a } 25 \\
\mathrm{~mm} \text {. Adicionalmente se } \\
\text { trató con una solución de } \\
\text { hidróxido de calcio a } 5 \% \\
\text { por protección al medio } \\
\text { alcalino de la pasta del } \\
\text { cemento. } \\
\text { Finalmente se trabajó } \\
\text { con } 2 \text { grupos de } \\
\text { muestras, los del tamiz } \\
\text { №4 y №6 }\end{array}$ & $\begin{array}{l}M(P) \\
M+0.5 \\
\% \\
M+25 \% \\
M+5 \%\end{array}$ & $\begin{array}{l}\text { Al ser una mezcla seca con la } \\
\text { proporción de a/c=0.55, se } \\
\text { afirma que es una mezcla } \\
\text { trabajable. } \\
\text { Cable resaltar que se añadió } 3 \% \\
\text { de cloruro de calcio como } \\
\text { acelerador de fragua. }\end{array}$ & 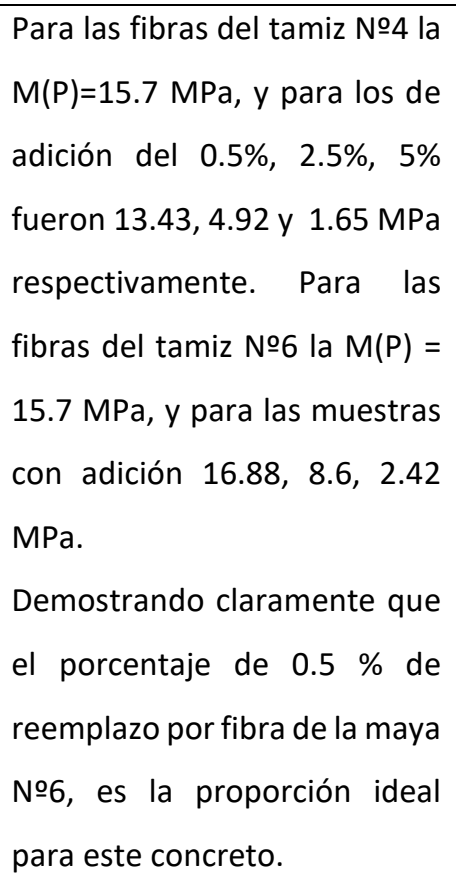 & 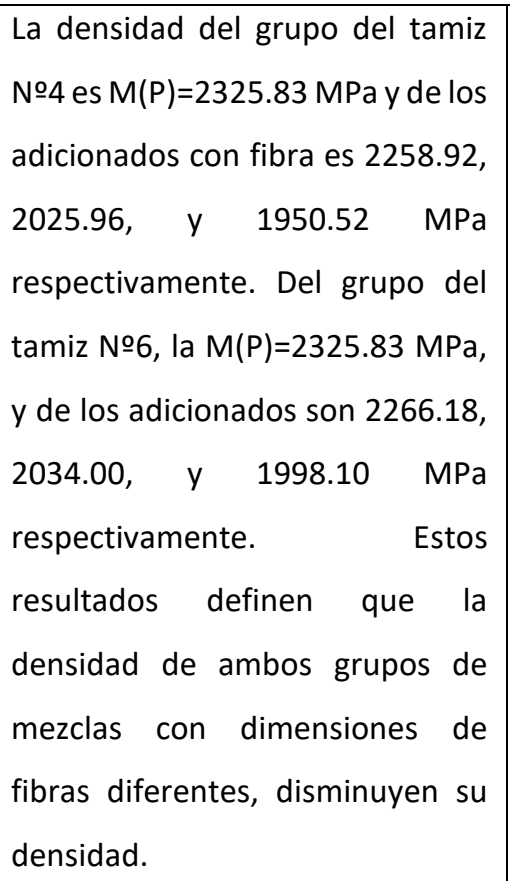 & Medellín & 2007 \\
\hline $\begin{array}{l}\text { (Muhamad, } \\
y \quad \text { otros, } \\
\text { 2013) }\end{array}$ & $\begin{array}{l}\text { Obtención del bagazo } \\
\text { crudo (sin tratamiento) }\end{array}$ & $\begin{array}{l}M(P) \\
M+1 \% \\
M+3 \% \\
M+5 \%\end{array}$ & $\begin{array}{l}\text { En la prueba de penetración el } \\
\text { concreto agregado con bagazo } \\
\text { de caña de azúcar permitió que } \\
\text { la aguja del aparato Vicat para } \\
\text { penetrar en el hormigón fresco } \\
\text { dure más tiempo. A dos horas, la } \\
\text { muestra de control ya no se }\end{array}$ & $\begin{array}{l}M(P)=28.97 \\
M+1 \%=48.83 \\
M+3 \%=42.00 \\
M+5 \%=36.40 \\
(N / m m 2)\end{array}$ & $\begin{array}{l}\text { Aplicando un carga de } 0.2 \mathrm{KN} / \mathrm{s} \text {, se } \\
\text { obtiene: } \\
M(P)=1.60 \\
M+1 \%=2.20 \\
M+3 \%=2.00 \\
M+5 \%=1.80\end{array}$ & Malaysia & 2013 \\
\hline
\end{tabular}


INGENIUM ET POTENTIA

Revista Electrónica M

Año III. Vol III. N5. Julio - Diciembre. 202

Hecho el depósito de Ley: FA20190000s2

FUNDACIÓN KOINONIA (F.K).

Santa Ana de Coro, Venezuela.

Sócrates Pedro Muñoz Pérez; Ramiro Stalin Coronel Camino; Julio César Vargas Villafuerte

\begin{tabular}{|c|c|c|c|c|c|c|c|}
\hline & & & $\begin{array}{l}\text { puede penetrar mientras el } \\
\text { hormigón agregado con } 1 \% \text { de } \\
\text { bagazo de caña de azúcar } \\
\text { todavía se puede penetrar en un } \\
\text { promedio de } 12,33 \mathrm{~mm} \text { a las dos } \\
\text { horas. Para el bagazo de caña de } \\
\text { azúcar al } 5 \% \text {, la muestra no } \\
\text { puede penetrar en cinco horas. }\end{array}$ & & $\begin{array}{l}(\mathrm{N} / \mathrm{mm} 2) \text {,Adicionalmente se hizo } \\
\text { pruebas de tracción aplicando } \\
\text { una carga de } 0.94 \mathrm{KN} / \mathrm{s} \text { donde los } \\
\text { resultados fueron: } \\
\mathrm{M}(\mathrm{P})=1.45 \\
\mathrm{M}+1 \%=2.10 \\
\mathrm{M}+3 \%=2.00 \\
\mathrm{M}+5 \%=1.70 \\
(\mathrm{~N} / \mathrm{mm} 2)\end{array}$ & & \\
\hline $\begin{array}{l}\text { (Huertas, } \\
\text { Martinez, \& } \\
\text { Espitia, } \\
\text { 2019) }\end{array}$ & $\begin{array}{l}\text { Se lavó la fibra con agua } \\
\text { destilada y se dejó secar } \\
\text { a temperatura ambiente } \\
\text { por } 30 \text { días, } \\
\text { posteriormente se } \\
\text { seleccionan fibras de } 2 \text { a } \\
6 \quad \mathrm{~cm} \text { de longitud } \\
\text { aproximado y } \quad \text { con } \\
\text { diámetro } 0.157 \quad \mathrm{~mm} \\
\text { aproximado }\end{array}$ & $\begin{array}{l}M(P) \\
M+0.4 \\
\% \\
M+0.6 \\
\% \\
M+0.8 \\
\%\end{array}$ & - & $\begin{array}{l}\text { Se analizó a los } 7,14 \text { y } 28 \text { días, } \\
\text { pero se consideran los } \\
\text { resultados últimos ( } 28 \text { días) en } \\
2750,2400,2750 \text { y } 2390 \text { PSI. } \\
\text { Si se sabe que se tiene como } \\
\text { referencia uno concreto de } \\
\text { diseño de } 3000 \text { PSI, se asume } \\
\text { que el espécimen de } 0.6 \% \text { BF } \\
\text { es la proporción ideal. }\end{array}$ & - & Bogotá & 2019 \\
\hline
\end{tabular}


INGENIUM ET POTENTIA

ría y Arquitectura

Año III. Vol III. No5. Julio - Diciembre. 202

Hecho el depósito de Ley: FA2019000052

FUNDACIÓN KOINONIA (F.K)

Santa Ana de Coro, Venezuela.

Sócrates Pedro Muñoz Pérez; Ramiro Stalin Coronel Camino; Julio César Vargas Villafuerte

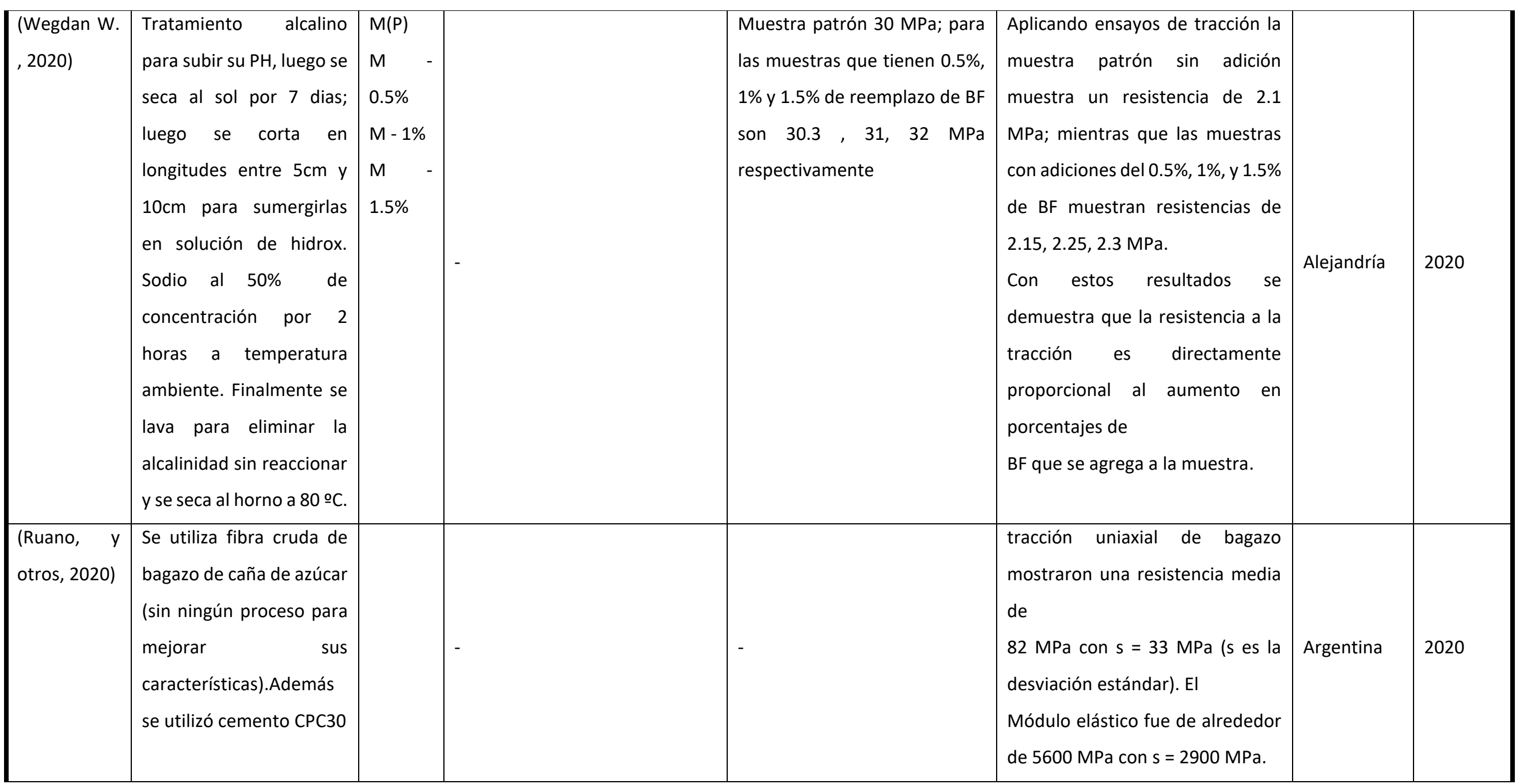


INGENIUM ET POTENTIA

Básicas, Ingeniería y Arquitectura

Año III. Vol III. N5. Julio - Diciembre. 202

Hecho el depósito de Ley: FA2019000052

FUNDACIÓN KOINONIA (F.K)

Sócrates Pedro Muñoz Pérez; Ramiro Stalin Coronel Camino; Julio César Vargas Villafuerte

\begin{tabular}{|c|c|c|c|c|c|c|c|}
\hline $\begin{array}{l}\text { (Ribeiro, } \\
\text { Yamamoto, } \\
\& \\
\text { Yamashiki, } \\
2020)\end{array}$ & $\begin{array}{l}\text { Remojo por } 30 \mathrm{~min} \text { en } \\
\text { agua a } 30^{\circ} \mathrm{C}\end{array}$ & $\begin{array}{l}M(P) \quad y \\
M+B F 2 \\
M+B F 5\end{array}$ & $\begin{array}{l}\text { La muestra de control tuvo un } \\
\text { revenimiento de } 6.7 \mathrm{~cm} \text {; } \\
\text { mientras que la muestra de BF2 } \\
\text { cayó } 5.8 \mathrm{~cm} \text {; finalmente la } \\
\text { muestra BF5 disminuyó en } 3.5 \\
\mathrm{~cm} \text {. }\end{array}$ & $\begin{array}{l}\text { Aproximadamente son } 47.50 \text {, } \\
46.00 \text { y } 39.00 \quad(\mathrm{~N} / \mathrm{mm} 2) \\
\text { respectivamente. }\end{array}$ & $4.63,4.77,4.83(\mathrm{~N} / \mathrm{mm} 2)$ & Kyoto & 2020 \\
\hline
\end{tabular}




\section{CONCLUSIONES}

La escoria de bagazo que es retenida en el tamiz de $45 \mu \mathrm{m}$ proporciona la mejor actividad puzolánica.

Quemando el material entre los $600-800^{\circ} \mathrm{C}$ y moliendo a $120 \mathrm{~min}$ da el $100 \%$ de actividad puzolánica.

Podríamos concluir que entre el $20-30 \%$ de CBCA mejora la trabajabilidad y la resistencia a compresión y a la flexión.

La fibra de bagazo de caña de azúcar, cumple con mejorar la propiedad mecánica del concreto, siendo ideal, el uso de fibra procesada, entre 5 y $15 \mathrm{~cm}$ de longitud de fibra. El reemplazo de fibra de bagazo de caña de azúcar en relación al peso de agregados, cumple mejorando la resistencia a la compresión, tracción; siendo los porcentajes más adecuados entre 0.5 hasta el $3 \%$; estos porcentajes no solo mejoran las propiedades del concreto, sino también disminuyen el volumen de agregados y cemento que se utilizarían en la mezcla reduciendo su costo, y sin alterar su calidad y propiedades.

En el caso que se desee, elaborar una mezcla considerando proporciones de acuerdo a volúmenes, el concreto con fibra de bagazo de caña de azúcar, sería un concreto más liviano, pero con buenas características funcionales estructurales.

La fibra de bagazo de caña de azúcar incorporada a la mezcla de concreto tiende a ampliar el tiempo de fraguado, superando las 2 horas, según el ensayo de penetración con la aguja Vicat.

\section{FINANCIAMIENTO}

No monetario.

\section{AGRADECIMIENTO}

A la Escuela Profesional de Ingeniería Civil de la Universidad Señor de Sipán por el apoyo institucional. 


\section{REFERENCIAS}

Abdolkarim Abbasi, \& Amin Zargar. (2013). Using bagasse ash in concrete as Pozzolan, Middle-East. Journal of Scientific Research, 13(1990-9233 ), 716719.

Abdulkadir, T.S., Oyejobi, D.O, \& Lawal, A.A. (2014). Evaluation of sugarcane bagasse ash as a replacement for cement in concrete works. ACTA TEHNICA CORVINIENSIS - Bulletin of Engineering, 7, 71-76.

Almeida, F., Sales , A., Moretti , J., \& Mendes, P. (2015). Sugarcane bagasse ash sand (SBAS): Brazilian agroindustrial by-product for use in mortar. Construction and Building Materials, 82, 31-38. doi:http://dx.doi.org/10.1016/j.conbuildmat.2015.02.039

Amin, N.-u. (2011). Use of Bagasse Ash in Concrete and Its Impact on the Strength and Chloride Resistivity. Journal of Materials, 23, 717-720.

Andrade Neto , J., Santos de França, M., Santana de Amorim Júnior, N., \& Véras Ribeiro, D. (2020). Effects of adding sugarcane bagasse ash on the properties and durability of concrete. Construction and Building Materials, 266, 1-13.

Asma , A., NasirShafiq, MuhdFadhilNuruddin , \& Fareed, A. (2014). Compressive strength and microstructure of sugar cane bagasse ash concrete, Research Journal of Applied Sciences. Engineering and Technology, 7, 2569-2577.

Bahurudeen, A., Wani, K., Abdul Basit, M., \& Santhanam, M. (2016). Assesment of Pozzolanic Performance of Sugarcane Bagasse Ash. American Society of Civil Engineers., 1-11. doi:10.1061/(ASCE)MT.1943-5533.0001361

Bayapureddy, Y., Muniraj, K., \& Gangireddy Mutukuru, M. (2020). Sugarcane bagasse ash as supplementary cementitious material in cement composites: strength, durability, and microstructural analysis. Journal of the Korean Ceramic Society, 1-7. doi:https://doi.org/10.1007/s43207-020-00055-8

Berenguer, Nogueira, Marden, Barreto, Helene, \& De Melo. (2018). La influencia de las cenizas de bagazo de caña de azúcar como reemplazo parcial del cemento en la resistencia a la compresión de los morteros. Revista ALCONPAT, 8(1), 30-37. Obtenido de http://dx.doi.org/10.21041/ra.v8i1.187

Boontima , B., Noomhorm , A., Puttanlek, C., Uttapap, D., \& Rungsardthong, V. (2014). Mechanical Properties of Sugarcane Bagasse Fiber-Reinforced Soy Based Biocomposites. Springer Science+Business Media, 1, 1-10. doi:DOI 10.1007/s10924-014-0679-2 
Cabrera-Madrid, J., Escalante-García, J., \& Castro-Borges, P. (2016). Compression resistance of concretes with blast furnace slag. Re-visited state-of-the-art. ALCONPAT Journal, 64-83. Obtenido de http://dx.doi.org/10.21041/ra.

Chindaprasirt, P., Sujumnongtokul, P., \& Posi, P. (2019). Durability and Mechanical Properties of Pavement Concrete Containing Bagasse Ash. ScienceDirect, 1612-1626.

Chusilp, N., Jaturapitakkul, C., \& Kiattikomol, K. (2009). Effects of LOI of ground bagasse ash on the compressive strength and sulfate resistance of mortars. Construction and Building Materials, 23, 3523-3531. doi:10.1016/j.conbuildmat.2009.06.046

Deepika, S., Anand, G., Bahurudeen, A., \& Santhanam, M. M. (2017). Construction Products with Sugarcane Bagasse Ash Binder. Materials in Civil Engineering, 1-10. doi:10.1061/(ASCE)MT.1943-5533.0001999.

Duc, H., Yeong, N., \& My Ngoc, T. (2018). Fresh and hardened properties of selfcompacting concrete with sugarcane bagasse ash-slag blended cement. (Elsevier, Ed.) Construction and Building Materials, 138-147. Obtenido de https://doi.org/10.1016/j.conbuildmat.2018.07.029

Farnaz , B., Arjumend , M., \& Mehmood , A. (2019). Characterization of Sugarcane Bagasse Ash as Pozzolan and Infuence on Concrete Properties. Science and Engineering, 1-10. Obtenido de https://doi.org/10.1007/s13369$\underline{019-04301-y}$

G.C. Cordeiro, R.D. Toledo Filho, L.M. Tavares, \& E.M.R. Fairbairn. (2008). Pozzolanic activity and filler effect of sugar cane bagasse ash in Portland cement and lime mortars. Cement \& Concrete Composites, 30, 410-418. doi:10.1016/j.cemconcomp.2008.01.001

Hernández-Olivares, F., Medina-Alvarado, R. E., Burneo-Valdivieso, X. E., \& ZúñigaSuárez, A. R. (2020). Short sugarcane bagasse fibers cementitious composites for building construction. Construction and Building Materials, 247(118451), 117.

Huertas, L., Martinez, P., \& Espitia, M. (2019). Analysis of compression resistance property of concrete modified with sugarcane (Saccharum Officinarum) bagasse fibers). Instituto Español de Estudios Estratégicos (IEEE), 1-4. 
Jagadesh, P., Ramachandramurthy, A., \& Murugesan, R. (2018). Evaluation of mechanical properties of Sugar Cane Bagasse Ash concrete. Construction and Building Materials, 176, 608-617. doi:https://doi.org/10.1016/j.conbuildmat.2018.05.037

K. Ganesan, K. Rajagopal , \& K. Thangavel. (2007). Evaluation of bagasse ash as supplementary cementitious material. Cement \& Concrete Composites, 29, 515-524. doi: $10.1016 /$ i.cemconcomp.2007.03.001

K.Rekha, \& R.Thenmozhi. (2014). Evaluation of Mechanical properties of BAGcrete. Advanced Materials Research , 984-985, 693-697.

Lakshmi Priya, K., \& Ragupathy, R. (2016). Effect of sugarcane bagasse ash on strength properties of concrete. International Journal of Research in Engineering and Technology, 159-164.

Lathamaheswari, Kalaiyarasan, V., \& Mohankumar, G. (2017). Study on Bagasse Ash As Partial Replacement of Cement in Concreto. International Journal of Engineering Research and Development, 1-6.

Loh, Y., Sujan, D., Rahman, M., \& Das, C. (2013). Sugarcane bagasse -The future composite material A Literature Review. Resources Conservation and Recycling, 75, 14-22.

Lorca Aranda, P. (2014). Efecto de la adición de Hidróxido Cálcico sobre mezclas con alta sustitución de cemento por ceniza volante. Tesis Doctoral. Universidad Politécnica de Valencia, España.

Manjunath , R., \& Rahul, M. (2019). Properties of Sugarcane Bagasse Ash Blended Self-Compacting Concrete Mixes. Sustainable Construction, 265-274. doi:https://doi.org/10.1007/978-981-13-3317-0 24

Montakarntiwong, K., Chusilp, N., Tangchirapat, W., \& Jaturapitakkul, C. (2013). Strength and heat evolution of concretes containing bagasse ash from thermal power plants in sugar industry. Materia Is and Design, 413-420.

Muhamad , A., Mohammed , A., Zulkifli , A., Nazrin , D., Nooraina , M., Siti Khadijah , C., . . . Mohamad , Y. (2013). Usage of Sugarcane Bagasse as Concrete Retarder. International Journal of Business and Technopreneurship, 3, 495503.

Murugesan, Vidjeapriya, \& Bahurudee. (2020). Sugarcane Bagasse Ash-Blended Concrete for Effective Resource Utilization Between Sugar and Construction Industries. Society for Sugar Research \& Promotion , 1-12. Obtenido de https://doi.org/10.1007/s12355-020-00794-2 
Nasir, S., Asma, A. H., Muhd, F. N., \& Hashem , A. (2016). Effects of sugarcane bagasse ash on the properties of concreto. Institution of Civil Engineers, 1-10. Obtenido de http://dx.doi.org/10.1680/jensu.15.00014

Osorio Saraz, J., Varón Aristizabal, F., \& Herrera Mejía, J. (2007). Comportamiento mecánico del concreto reforzado con fibra de bagazo de caña de azúcar. DYNA, 69-79.

Otoko, G. (2014). Use of bagasse ash as partial replacement of cement in concrete. International Journal of Innovative Research \& Development,, 3, 285-289.

Rajasekar, A., Arunachalam, K., Kottaisamy, M., \& Saraswathy, V. (2018). Durability characteristics of Ultra High Strength Concrete with treated sugarcane bagasse ash. Construction and Building Materials, 350-356. Obtenido de https://doi.org/10.1016/j.conbuildmat.2018.03.140

Ribeiro, B., Yamamoto, T., \& Yamashiki, Y. (2020). A Study on the Reduction in Hydration Heat and Thermal Strain of Concrete with Addition of Sugarcane Bagasse Fiber. Journal materials, 13, 1-14.

Ruano, G., Bellomo, F., López, G., Bertuzzi, A., Nallim, L., \& Oller, S. (2020). Mechanical behaviour of cementitious composites reinforced with bagasse and hemp fibers. Construction and Building Materials, 1-9.

Sajjad, A. M., Jamaluddin , Wan, I., Abd , H. A., Abdul , A., Samiullah , S., \& Nizakat A. (2017). Utilization of sugarcane bagasse ash in concrete as partial replacement of cement. IOP Publishing Ltd, 1-9. Obtenido de https://doi.org/10.1088/1757-899X/271/1/012001

Sales, A., \& Lima, S. (2010). Use of Brazilian sugarcane bagasse ash in concrete as sand replacement. Waste Management, 30, 1114-1122. doi:10.1016/j.wasman.2010.01.026

Somna , R., Jaturapitakkul , C., Rattanachu, P., \& Chalee , W. (2012). Effect of ground bagasse ash on mechanical and durability properties of recycled aggregate concrete. Materials and Design, 36, 597-603. doi:10.1016/j.matdes.2011.11.065

Sounthararajan, V., Sivasankar, S., Vinodh Kumar, R., Modak, N., \& Dilli Bai, K. (2019). Valorization of Specially Designed Concrete by Using Sugarcane Bagasse Ash and Inducing the Special Benefits of Waste Tin Fiber Reinforced Concrete. International Journal of Innovative Technology and Exploring Engineering, 220224. doi:10.35940/ijitee.L3589.1081219 
Sundaravadivel , D., \& Mohana , R. (2018). Recent studies of sugarcane bagasse ash in Concrete and mortar: a review. Revista Internacional de Ingeniería, Investigación y Tecnología , 7, 306-312.

Tri Hatmoko, J., \& Suryadharma, H. (2019). Behavior of bagasse ash-calcium carbide residue stabilized soil with polyester fiber inclusion. Materials Science and Engineering, 1-12. doi:10.1088/1757-899X/620/1/012066

V.M. Sounthararajan, Y Stalin Jose, \& ,S. Sivasankar . (2019). Synergetic Effect of Sugarcane Bagasse Ash with Low Modulus of Fiber Reinforced Concrete. International Journal of Recent Technology and Engineering (IJRTE), 71717175 .

Wegdan W. , E.-N. (2020). Applicability of Using Natural Fibers for Reinforcing Concrete. Materials Science and Engineering, 809, 1-7. doi:10.1088/1757$\underline{899 \times / 809 / 1 / 012018}$

Xiong, W. (2018). Bagasse composites:A review of material preparation, attributes, and affecting factors. Thermoplastic Composite Materials, 31(8), 1112-1146.

Y.R.Loh, D.Sujan, M.E.Rahman, \& C.A.Das. (2013). Sugarcane bagasse-The future composite material :A literature review. Resources, conservation and recycling, 14-22.

C2021 por los autores. Este artículo es de acceso abierto y distribuido según los términos y condiciones de la licencia Creative Commons Atribución-NoComercial-Compartirlgual 4.0 Internacional (CC BY-NC-SA 4.0) (https://creativecommons.org/licenses/by-nc-sa/4.0/). 